\title{
Один путь - один хозяин? Нужен ли единый оператор Северного морского пути ${ }^{1}$
}

В.А. КРЮКОВ, член-корреспондент РАН, Институт экономики и организации промышленного производства СО РАН, Новосибирск

В статье рассматриваются проблемы и следствия применения различных подходов к формированию системы управления (регулирования) функционированием трассы Северного морского пути.

По мнению автора, при тех возможностях, которыми располагает государство, современной ситуации развития Арктики в наибольшей степени отвечает система управления, учитывающая особенности различных сегментов экономики. А именно: хозяйственные функции единого оператора допустимы только при реализации проектов с доминирующим участием государства. В остальных случаях они ограничиваются вопросами координации и согласования интересов всех сторон, участвующих в обеспечении функционирования пути (включая отправителей и получателей грузов).

Ключевые слова: Арктика, Северный морской путь, единый оператор, функции управления, координация, развитие инфраструктуры, тарифы ледовой проводки, караванная проводка судов

\section{История вопроса и его актуальность}

Общепризнанны различия социально-экономических систем по отношениям собственности, роли рынка и государства, подходам к управлению государством и месту отдельного человека (именно человека, а не «личности») в экономике и обществе и многим другим важным признакам. Менее очевидно, что они характеризуются также неодинаковыми подходами к формированию технико-технологических подсистем в различных секторах экономики. При этом в разных социально-экономических системах, функционирующих в один и тот же промежуток исторического времени (исчисляемый не годами, а по крайней мере, десятилетиями), могут применяться одинаковые базовые принципы и элементы создания компонентов технологических подсистем, одни и те же достижения в области естествознания, но из-за кардинальных отличий в «компоновке» и условиях их

\footnotetext{
${ }^{1}$ Статьяподготовлена в рамкахпрограммы Президиума РАН № 13 , проект XI.174. (0325-2015-0011) «Север и Арктика Азиатской России - взаимодействие экономики и ресурсно-природной среды на новой технологической и институциональной основе».
} 
применения результаты могут оказаться принципиально различными.

Примером может служить уникальная транспортная система, созданная в Советском Союзе - Северный морской путь (СМП). Его особенность - очень тесная связь процессов транспортировки грузов морскими судами с функционированием портового хозяйства вдоль трассы пути, наличием системы навигационного и гидрографического обеспечения, а также нацеленность на реализацию проектов освоения минерально-сырьевых ресурсов в «высоких широтах» и решение оборонных и геостратегических задач. В 1932 г. была создана и соответствующая структура управления - Главное управление Северного морского пути («Главсевморпуть») при Правительстве СССР, с очень широкими и полномочиями по осуществлению хозяйственных и транспортных функций.

«Ядром» (основой устойчивости) сформированной технологической подсистемы стал уникальный ледокольный флот (прежде всего, атомные ледоколы, многие из которых не имели аналогов в мире), который позволил перейти в 1970-е годы на круглогодичную навигацию в западном секторе Арктики. Масштабы решаемых задач требовали и соответствующих подходов - заблаговременного планирования всех морских операций, значительных единичных мощностей ледоколов, караванной проводки судов (т. е. одновременной транспортировки колоссальных партий груза), управления и диспетчеризации из единого центра (см. ниже).

Важнейшее условие - соответствие масштабов на всех этапах и стадиях, от проекта по освоению минерально-сырьевых ресурсов до караванов, ледоколов и портовых сооружений. Эффективность такой подсистемы обеспечивалась экономией на масштабе. Проигрывая в гибкости (и, соответственно, в учете фактора времени), данная система выигрывала за счет относительно низких удельных издержек в конечном звене стоимостной цепочки.

При этом неизбежен вопрос: что будет, если, во-первых, нарушить в рамках данной цепочки соответствие масштабов всех ее звеньев - от проектов до перевозимых партий грузов, и, во-вторых, учесть «фактор времени» (иными словами, стоимость денег)? Ответ вполне очевиден - данная система в скором будущем потеряет былую привлекательность. Не из-за того, что она плоха, а потому, что создана для реализации целей и задач 
в другой «системе координат» (не экономических, а физических объемы перевозимых грузов).

Как быть в таком случае с перевозкой грузов и освоением Арктики в современных условиях?

Ответ в общем очевиден - нужны более гибкие подходы к учету особенностей различных составляющих единой цепочки формирования стоимости услуг. Это вовсе не означает немедленной ликвидации того, что было создано ранее и чем у нашей страны есть все основания гордиться. В частности, необходим учет особенностей разных грузоотправителей и грузополучателей. Не только физическое перемещение груза является целью работы транспортной системы, но и предоставление данной услуги в срок и с необходимым «качеством» (конкурентный тариф, учет запросов потребителя, минимизация перевалок и излишних процедур оформления).

Россия по-прежнему, как и много-много лет назад, стоит на «пороге» Арктики. Новизна ситуации связана не только с разработкой минеральных ресурсов и нефтегазовыми миражами (которые так сильны, что далеко не самое выдающееся и «запрограммированное» трудом советских геологов месторождение на шельфе Карского моря получило гордое имя «Победа» [1]), но и, прежде всего, со стремительным формированием глобального экономического пространства, которое все настойчивее «проникает» в Арктику (несмотря на взлеты и падения объемов перевозок грузов в этом районе земного шара в последние годы).

На этапе продвижения нашей страны на восток был найден транспортный путь (как тут не вспомнить М.К. Сидорова, А.М. Сибирякова, С.В. Востротина [2], а также таких увлеченных людей, как, например, художник А. Борисов [3] и многие другие). Затем, в условиях социалистической индустриализации [4-5], создана транспортная система (О. Ю. Шмидт и большая плеяда ученых и практических работников занимались реализацией этой задачи на протяжении весьма длительного периода времени [6]). На нынешнем этапе ситуация кардинально изменилась - требуется найти решение в период затянувшихся политических и экономических трансформаций ${ }^{2}$.

${ }^{2}$ Нельзя не отметить ту колоссальную роль в активизации обсуждения проблем СМП в 1990-2010 гг., которую сыграл академик А. Г. Гранберг (1936-2010 гг.) [7]. 
Идеальный вариант - сохранить все лучшее из созданного ранее, привнести то, что обусловлено новым временем и новыми возможностями (лучшим знанием Арктики, прежде всего), и сформировать адекватный подход к функционированию Северного морского пути, увязать его перспективы с решением проблем социально-экономического развития «высоких широт». Увы, многое из того, что было создано ранее, сегодня разрушено и пришло в негодность (в частности, порты и инфраструктура в восточном секторе Арктики).

В последние годы проблемы Арктики и Северного морского пути обсуждаются на самом высоком уровне. Так, в Мурманске 9 марта 2016 г. состоялось заседание президиума Госкомиссии по вопросам развития Арктики под председательством заместителя председателя Правительства РФ Д. О. Рогозина. На данном совещании было дано поручение «... представить в Правительство Российской Федерации в срок до 20 апреля... материалы, в том числе о создании единого транспортно-логистического оператора в Арктической зоне Российской Федерации, с целью организации перевозок по трассе Северного морского пути» [8].

Поэтому возникает вполне закономерный вопрос о том, как и какие функции может (и должен) в современной экономике выполнять данный единый оператор, можно ли перенести в современную жизнь подходы всеохватывающего «единения» всех звеньев транспортной системы, которые были присущи «Главсевморпути» периода славных лет индустриализации и покорения природы?

Следует заметить, что для обсуждения данных вопросов требуется уточнить исходные термины, прежде всего - «транспортно-логистический оператор». Вполне очевидно, что это - компания, осуществляющая все стадии, от получения грузов до их доставки потребителю. При этом она может либо выполнять подобные функции самостоятельно (или через свои филиалы и дочерние структуры), либо выступать в роли генерального оператора и передавать часть функций на контрактной основе другим компаниям, либо совмещать оба подхода и т. д. Не исключена и возможность осуществления операторских функций в «мягком формате» - при прямом участии в создании и поддержании 
условий мореплавания, а также информационной координации всех пользователей трассы Севморпути.

Независимо от применяемой схемы управления, основная ее направленность - гибкость и эффективность в предоставлении транспортных услуг, а также содействие решению социально-экономических проблем развития северных и арктических территорий России.

Наиболее сложная проблема - не столько разработка и подготовка логически выверенной схемы, сколько формирование процедур учета интересов и устремлений самых разных «стейкхолдеров» (от получателей грузов до строителей ледоколов и объектов транспортной инфраструктуры), а также выработка шагов по претворению задуманного на практике.

\section{Координировать или управлять?}

Подход к управлению (координации) развития и использования трассы Северного морского пути в значительной мере определяется тем, какие цели являются превалирующими и кто обеспечивает их достижение.

При решении подобных задач доминируют два подхода:

- при возникновении сложной комплексной социально-экономической проблемы (развитие трассы СМП также можно считать такой проблемой) в России наметилось стремление к подготовке «именных» (или специализированных) законов прямого действия (например, «Закон об Арктике», о необходимости которого говорят представители северных территорий в Госдуме уже немало лет);

- проявилась тенденция передать решение всех сложных проблем координации, взаимодействия участников, имеющих разные интересы, «единому координирующему органу» с широкими полномочиями (якобы ему виднее, и в процессе работы он всегда найдет приемлемое решение).

К сожалению, ни один из этих подходов в современном мире и экономике не работает (и, следует добавить, работать не может). Причины - опережающий рост издержек, низкая экономическая эффективность и постоянная необходимость финансовой поддержки извне.

В России нет ни достаточных финансовых ресурсов, ни реальной возможности административным путем «привести» интересы 
всех участников к единому знаменателю (появились новые субъекты хозяйственных отношений, созданы органы госуправления с определенными функциями, сформирована разветвленная (хотя и весьма противоречивая) нормативно-правовая база).

Нельзя и неправомерно сосредоточивать в одном органе управления контрольные, управленческие (регулирующие) и хозяйственные функции. Это один из постулатов формирования эффективной системы органов государственного управления (к сожалению, Россия заплатила за его осознание колоссальную цену на протяжении всей своей истории, и современный этап ее развития - не исключение).

Система управления (координации) трассы СМП должна основываться на новых подходах к реализации подобных масштабных проектов и преследовать в качестве главной цели обеспечение социально-экономического развития Севера и Арктики России. Причем на основе приемлемых и допустимых по современным меркам социальных, экономических и технологических решений.

\section{О целях и задачах СМП в свете современных тенденций}

Фактически развитие трассы Северного морского пути преследует две цели:

- геостратегическую (или, как пишут политические обозреватели, - «демонстрацию флага»);

- социально-экономическую - развитие северных и арктических территорий (сюда входят и судоходство, и реализация крупных проектов, и, как одна из важнейших подцелей, обеспечение современных условий проживания и традиционной деятельности народов Севера).

Эти важнейшие цели связаны между собой. «Демонстрацию флага» нет нужды проводить в форме акций и демаршей международного «звучания», если в регионах Арктики и Севера России успешно решаются социально-экономические проблемы и развивается хозяйственная деятельность.

Реализация социально-экономической цели предполагает, прежде всего, создание условий и предпосылок для повышения эффективности проектов освоения северных территорий и роста 
уровня жизни проживающего населения. Северный морской путь, с этой точки зрения, призван обеспечивать:

- завоз грузов и товаров, имеющих большое значение с точки зрения жизнеобеспечения и реализации проектов;

- вывоз произведенных продуктов и материалов (в основном для последующей переработки в местах, приближенных к рынкам сбыта готовой продукции);

- транзит судов - как с запада на восток, так и в обратном направлении.

В этом качестве на решения по развитию СМП оказывают влияние (в какой-то степени конкурируют) те тенденции, которые складываются в морских перевозках не только в Арктике, но и в целом в глобальной экономике. Основной тренд в развитии транспортно-логистических систем и комплексов в мире состоит в формировании подходов, ориентированных на нужды клиента (клиентоориентированных систем). Это означает, прежде всего:

- гибкость в предоставлении услуг и сервисов (таких, как транспортировка грузов);

- стремление к быстрейшему возврату вложенных средств.

Именно поэтому, например, полностью прекратились лесоперевозки по Северному морскому пути в связи с коренным изменением модели хозяйствования в лесной отрасли - компании стали менее крупными, снизились объемы заготавливаемых партий леса, наблюдается стремление к быстрой оборачиваемости финансовых ресурсов и проч. (никто не будет ждать целый сезон, чтобы отправить партию лесопродукции на рынок).

В связи с этим в мире растет интерес к судам повышенного ледового класса (не столько к ледоколам, сколько к специализированным сухогрузам, танкерам и т. д.). Такие суда, при значительно большей их стоимости, обеспечивают необходимую гибкость в выборе маршрутов, условий мореплавания, дают возможность ускоренной доставки грузов. В определенном смысле имеет место аналогия конкуренции грузоперевозок большегрузными автопоездами с железной дорогой, которая ее постоянно проигрывает.

Результат - повышение конкурентоспособности всей цепочки, от создания продукции на Севере и до ее реализации в другом регионе. 


\section{Особые условия мореплавания}

Работа Северного морского пути связана с целым рядом повышенных рисков - климатических, навигационных (льды, гидрография), технических. Поэтому вполне очевидно, что организация перевозок по трассе СМП должна основываться на учете двух групп обстоятельств - экономической гибкости и безопасности.

Гибкости в большей степени отвечает сочетание традиционных схем мореплавания (караваны с ледокольной проводкой) с возможностью одиночного плавания судов. Безопасность при этом обеспечивается не только характеристиками судов, но и условиями сопровождения мореплавания (навигация, гидрография).

В свою очередь, характеристики судов служат основанием для допуска их на трассу СМП в определенное время года [9] (данная практика реализуется ныне действующей Администрацией СМП), в сочетании со страхованием. Однако страхование весьма затруднено из-за отсутствия на трассе спасательных и вспомогательных служб и услуг, а также вследствие хронического недостатка необходимой портовой инфраструктуры (ее бедственного состояния, прежде всего, в восточном секторе Арктики).

В целом безопасность обеспечивается рядов обстоятельств:

- сертификацией судов (в том числе в рамках процедур их страхования);

- условиями допуска на трассу;

- обеспечением навигации, оказания помощи и поддержки судам, попавшим в затруднительные обстоятельства;

- наличием портовой инфраструктуры вдоль трассы.

Причем все составляющие такой системы безопасного судоходства очень тесно связаны и ориентированы на «разумного пользователя» трассы - никому не придет в голову рисковать репутацией и нести колоссальные материальные и финансовые риски, отправляя в плавание неприспособленное судно (сумма страховых вычетов превысит самые смелые ожидания предполагаемой выгоды).

\section{Функции и роль координатора}

Из представленного выше, на наш взгляд, вытекает необходимость разделения всех видов деятельности по организации работы Северного морского пути на три основных составляющих: 
- улучшение условий судоходства;

- инфраструктурное обеспечение вдоль трассы;

- собственно судоходство.

Обеспечение условий судоходства - навигация и оказание помощи в чрезвычайных ситуациях. Навигацию могут осуществлять сертифицированная лоцманская служба (службы), а также действуюшая в настоящее время Администрация СМП. К числу организаций, которые призваны этим заниматься, можно отнести Росгидромет РФ и МЧС РФ (целесообразно их функции в этой области обозначить более четко).

Инфраструктурой должны заниматься три основные группы действующих лиц:

1) Минобороны РФ, Минтранс РФ (плюс проекты в рамках деятельности «институтов развития»);

2) компании и хозяйствующие субъекты (ОАО «Ямал-СПГ», ОАО «ГазпромНефть», ОАО «Норильский никель» и др.);

3) Правительство РФ и субъекты РФ (нельзя не отметить «подвижничество» Ямало-Ненецкого АО).

Судоходство могут осуществлять все компании, прошедшие соответствующую сертификацию судов. Формат получения такой услуги, как «ледовая проводка», каждая компания для себя решает сама. Централизованно определямые «услуги ледокольного флота» неприемлемы и недопустимы. Ледокольный флот, «демонстрирующий флаг», базовое финансирование получает за счет государства и в рамках выполнения им государственных геостратегических задач. Коммерческие компании пользователи трассы СМП - прибегают к услугам ледовой проводки (если они им необходимы) на основе прозрачных тарифов, подлежащих согласованию с антимонопольным ведомством.

С учетом всего сказанного представляется необходимым и уместным ограничение задач и функций предполагаемого «Оператора СМП» такими направлениями деятельности, как:

- предоставление площадки для обсуждения позиций и соображений по функционированию СМП всеми заинтересованными сторонами (грузоотправители, грузополучатели и транспортники) (известный аналог - саморегулируемая организация НП «Совет рынка», которая обеспечивает функционирование коммерческой инфраструктуры оптового рынка электроэнергии); 
- оказание услуг по навигации мореплавания по трассе Севморпути (только для сертифицированных и застрахованных грузоперевозчиков). Здесь важно наличие связи со страхованием и получением кодов доступа к навигационным системам и актуальным базам климатических данных и сведений по ледовой обстановке.

Не следует подменять функции МЧС, Росгидромета и прочих федеральных структур, присутствие и участие которых в выполнении определенных задач, в том числе и на трассе СМП, задано их функциями, закрепленными в нормативных документах. Не следует смешивать информирование и объединение усилий разных участников с функциями хозяйственного руководства и управления (кому, когда и как транспортировать грузы, каким маршрутом обеспечивать доставку и проч.).

Опыт Ненецкого и Ямало-Ненецкого АO, а также Норильска говорит о том, что бурно развиваются те участки трассы, где силами бизнес-сообщества реализуется тот или иной значимый проект. Поэтому неправомерно данные интересы ущемлять и ставить в зависимость от транспортных и связанных с ними «координирующих» организаций. Важна не доставка грузов сама по себе, а тот социально-экономический результат, который данная деятельность обеспечивает в районах Арктики и Севера. При этом, однако, вопросы доступа третьих лиц к создаваемым инфраструктурным объектам необходимо определять заблаговременно.

С экономической точки зрения, критерии эффективности всей цепочки трассы СМП, от проекта до полученного в месте потребления продукта, - это приемлемые издержки и возврат инвестиций. А основной результат - социально-экономическое развитие территорий Арктики и Севера России. Социальноэкономическое развитие не может базироваться на дотациях и исключениях из правил: рано или поздно такая система деградирует и становится обузой для экономики и макрорегиона, и страны в целом.

Если же мы забываем об экономической составляющей и руководствуемся геостратегическими интересами, реализуется «старый, но верный» административно-командный принцип (план, сроки, исполнители, госфинансирование). Однако современные 
финансовые и экономические возможности страны не позволяют этого делать в рамках обширной программы: времена затратных амбициозных проектов ушли в прошлое. Вместе с тем использование механизмов государственно-частного партнерства открывает возможность для поэтапной реализации инфраструктурных проектов по трассе СМП [10].

\section{СМП и Арктическая трасса}

Все зарубежные пользователи разделяют две трассы - Северный морской путь («внутренняя российская транспортная артерия») и Northern Passage (Арктическая трасса - международная артерия, проходящая в международных территориальных водах по «полярной арктической дуге»). Решение о выборе трассы определяется не количеством ледоколов, а транспортными тарифами и наличием страхователя. Именно последнее обстоятельство предопределило наблюдаемое в последний год резкое снижение пробудившегося ранее интереса международных перевозчиков к данному маршруту.

\section{Что наиболее важно?}

В современной экономике формы и способы доставки грузов определяют отправитель и получатель, они же принимают на себя при этом значительную долю возникающих рисков. Это способствует росту экономической эффективности работы любой хозяйственной системы (Северный морской путь - не исключение, несмотря на наличие многих значимых специфических черт и исторических особенностей). Важнейший элемент всей системы работы трассы СМП - соучастие всех заинтересованных сторон и ясное понимание интересов и задач каждого.

В качестве соображений рекомендательного свойства считаю необходимым подчеркнуть следующее:

- неправомерно смешение и объединение в рамках одного управляющего (координирующего) органа функций контроля, обеспечения функционирования и, собственно, хозяйственной деятельности;

- в России создан целый ряд органов управления, функции которых «выходят» на решение задач СМП, необходимы лишь 
определенная ревизия и стыковка их по регламентам и срокам реализации в рассматриваемом конкретном случае;

- требуется координация - в форме учета мнений и позиций всех участвующих сторон - как грузоотправителей, так и грузополучателей и собственно транспортных организаций; целесообразно создать «Совет пользователей СМП» с правами и полномочиями рекомендательно-предписывающего характера (решение совета обязательно для всех его участников);

- целесообразна увязка процедур допуска к плаванию по трассе СМП не только с сертификацией судов, но и со страхованием;

- услуги ледовой проводки необходимо осуществлять на основе прозрачных и утвержденных антимонопольными ведомствами тарифов за реально оказанные услуги; решение о получении данной услуги принимает грузоотправитель или грузополучатель (с учетом условий страхования и характеристик используемых для перевозки судов);

- формирование и развитие портовой и терминальной инфраструктуры вдоль трассы СМП должны осуществляться с учетом реализуемых бизнес-сообществом проектов, а также интересов и возможностей государства (как в целом, так и отдельных субъектов Федерации); функции координации работ по созданию подобной инфраструктуры в большей степени отвечают задачам Минтранса РФ;

- важнейшая задача налаживания современной системы работы СМП - обеспечение безопасности и своевременности реагирования на непредвиденные обстоятельства мореплавания в высоких широтах (МЧС РФ, Росгидромет, система связи и текущего мониторинга).

Необходимо отойти от иллюзии простых и «проверенных» решений, основанных на всевластии и всесилии единого оператора с широкими и даже чрезвычайными полномочиями. Главное в его деятельности - умение согласовывать разные интересы и находить взаимоприемлемые решения.

\section{Литература}

1. Николаев Я. В Карском море нашли запасы нефти и газа. URL:// http://rg.ru/2014/09/27/neft-site.html

2. Северная морская экспедиция Министерства путей сообщения на реку Енисей в 1905 году//Управление внутренних водных 
путей и шоссейных дорог. - Санкт-Петербург: типография И.Н. Кушнерев и Ко, 1906. - 94 с.

3. Борисов А. Великий Северо-Восточный морской путь. Великий речной путь из Сибири в Европу. - Санкт-Петербург: типография А. С. Суворина, 1910. - 52 с.

4. Рыбин С. В. Северный морской путь из Европы к устьям Оби и Енисея. Его экономическое значение для Сибири и степень использования в настоящее время//Комитет Северного морского пути. - Новониколаевск, 1924. - 90 с.

5. Гуков А.И. Город Тикси. - М.: Принтком, 2013. - 472 с.

6. Российская Арктика: современная парадигма развития / Под ред. А. И. Татаркина. - Санкт-Петербург: Нестор-История, 2014. - 844 с.

7. Проблемы Северного морского пути / Под ред. А.Г. Гранберга и В.И Пересыпкина. - М.: Наука, 2006. - 581 с.

8. О решении по итогам заседания президиума Госкомиссии по вопросам развития Арктики// Портал Правительства России. Поручения и их выполнение. - 2016. - 10 март. URL:// http://government.ru/ orders/22291/\#sel=

9. Ice Class Criteria. Appendix 2 to the Rules for Navigation in the Northern Sea Route water areas (items 10,11). URL:// http://www.arctic-lio.com/ nsr_iceclasscriteria

10. Крюков В. А., Севастьянова А. Е., Токарев А. Н., Шмат В. В. Обоснование направлений развития ресурсных территорий, как комплексная мезоуровневая проблема //Экономика региона. - 2015. - № 4. C.260-274.

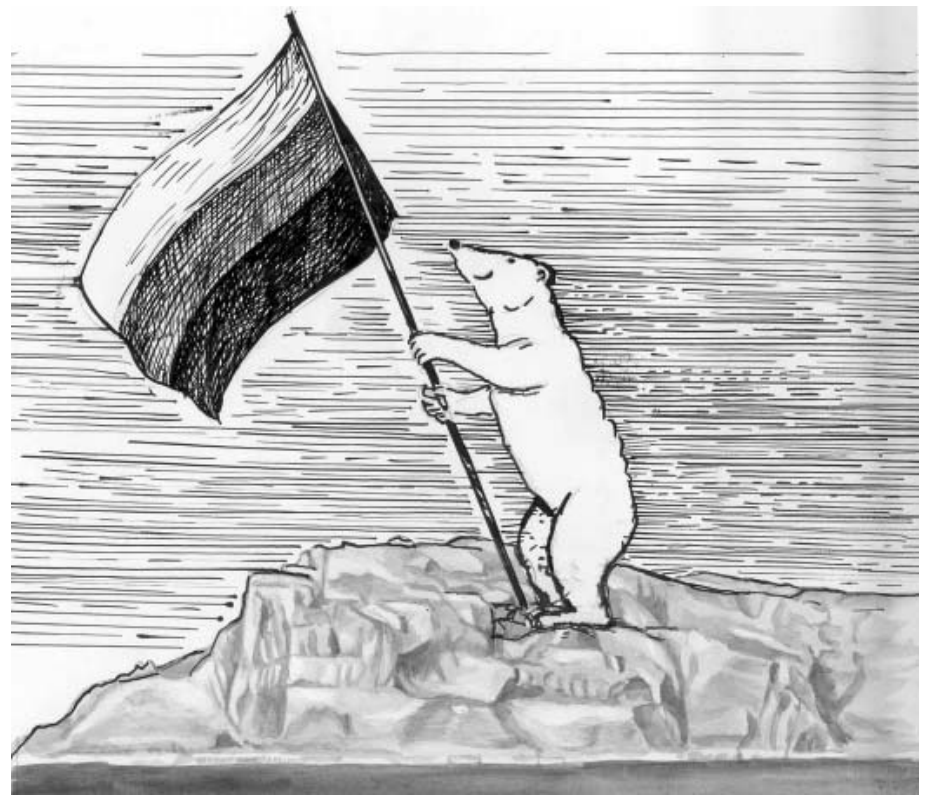

